\section{Esophagitis dissecans superficialis due to severe methotrexate toxicity}

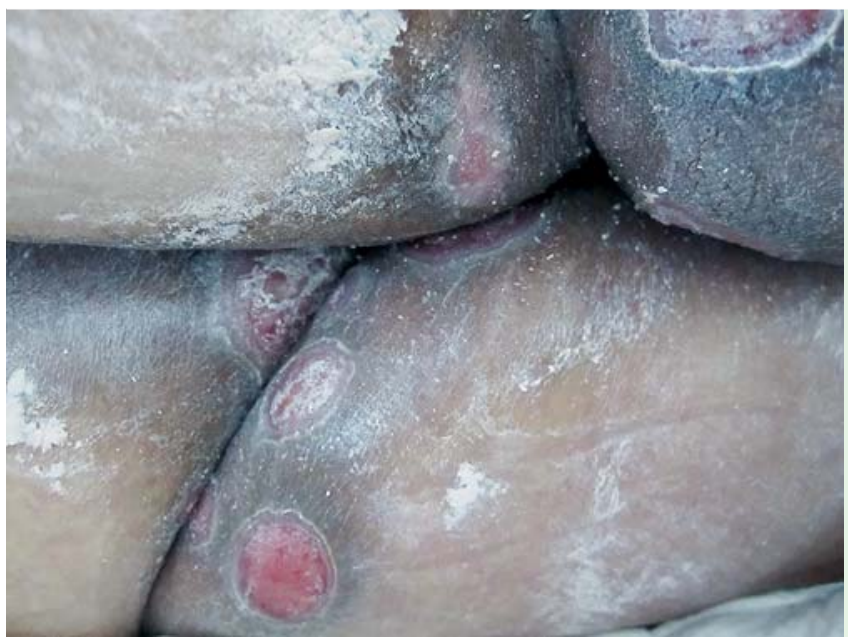

Fig. 1 Skin ulcers in a 56-year-old woman treated with methotrexate without folic acid for seronegative inflammatory arthritis. Multiple shallow ulcers, which were $1-2 \mathrm{~cm}$ in diameter and had red "beefy" bases, are shown in the gluteal folds and on the inner thighs.
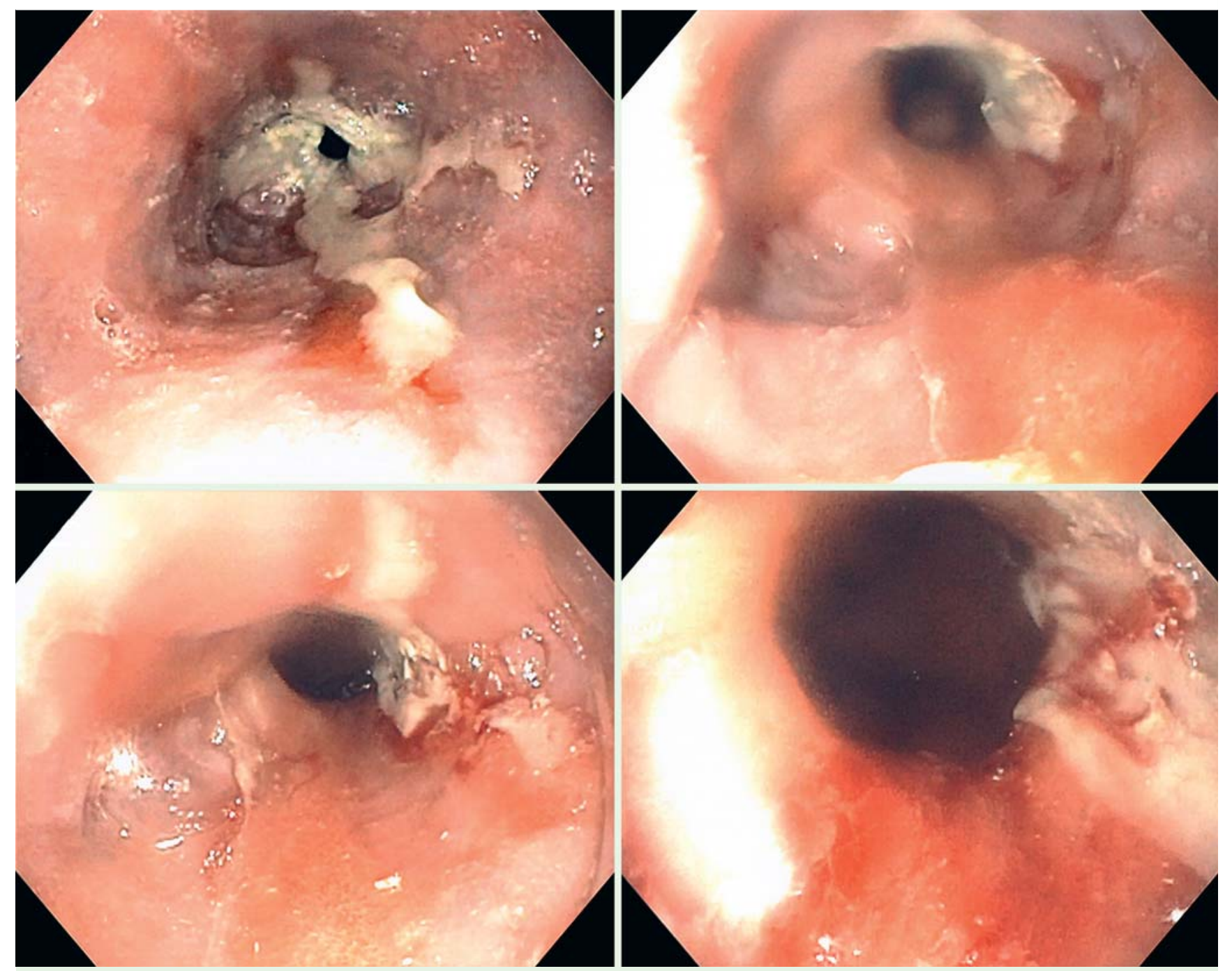

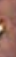
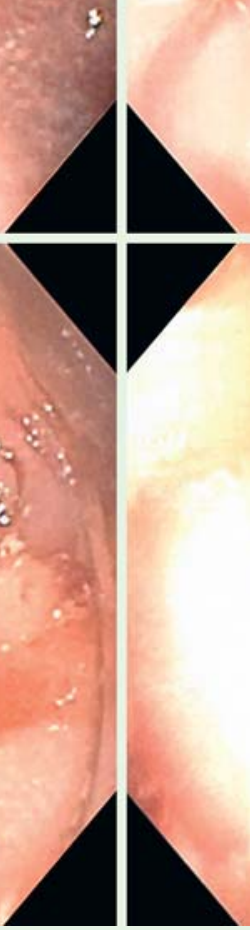

Fig. 2 Upper gastrointestinal endoscopy showing sloughing of large fragments of the esophageal squamous mucosa.
Esophagitis dissecans superficialis (EDS), also referred to as "sloughing esophagitis", is associated with the sloughing of large fragments of the esophageal squamous mucosa and is a rare endoscopic finding. The etiology is often unclear but it may result from thermal, chemical, or physical insults and has been reported in association with systemic diseases such as the autoimmune bullous dermatoses (pemphigus and pemphigoid) and certain medications [1-4].

A 56-year-old woman presented with a 1-month history of severe odynophagia, skin ulcers for 2 months ( $\bullet$ Fig. 1 ), oral ulcers for 4 months, and marked pancytopenia with folate deficiency. She was known to have seronegative inflammatory arthritis and had been treated with methotrexate without folic acid for at least 6 years. An upper gastrointestinal endoscopy revealed findings consistent with EDS ( Fig.2). An evaluation for 
other possible causes was negative and she was treated for presumed methotrexate toxicity. Intravenous "rescue" folinic acid, folic acid, and discontinuation of the methotrexate along with nutritional support resulted in improvement of the odynophagia and pancytopenia within 1 week and total resolution of her symptoms, the oral and skin ulceration, and the pancytopenia within 4 weeks. This is the first documented case of methotrexate toxicity presenting with EDS, skin and oral ulceration, and pancytopenia [4-6].

The diagnosis of EDS is made endoscopically and histopathologically. Endoscopy reveals an esophagus that seems filled with "gift-wrap paper" or with vertical fissures and sloughing of the whitish superficial epithelium. The histopathological findings are well described [2], but it is important for accurate diagnosis to give relevant clinical or endoscopic information to the pathologist $[1,2]$.

A high index of suspicion for methotrexate toxicity is necessary in patients on chronic methotrexate therapy who complain of odynophagia, particularly if they have associated risk factors (hypoalbuminemia, low folate levels, concomitant infections, concomitant use of more than five medications, and lack of folate supplementation) $[5,7,8]$. Methotrexate toxicity may be associated with EDS.
Endoscopy_UCTN_Code_CCL_1AB_2AC_3AH

Competing interests: None

\section{Khurram Abbass, Lauren Haveman, Elie Gertner}

Section of Rheumatology, Regions Hospital and Division of Rheumatology, University of Minnesota Medical School, Minneapolis, Minnesota, USA

\section{References}

1 Hokama A, Yamamoto Y, Taira K et al. Esophagitis dissecans superficialis and autoimmune bullous dermatoses: A review. World J Gastrointest Endosc 2010; 2: 252-256

2 Carmack SW, Vemulapalli $R$, Spechler SJ et al. Esophagitis dissecans superficialis ("sloughing esophagitis"): a clinicopathologic study of 12 cases. Am J Surg Pathol 2009; 33: 1789-1794

3 Purdy JK, Appelman HD, McKenna BJ. Sloughing esophagitis is associated with chronic debilitation and medications that injure the esophageal mucosa. Mod Pathol 2012; 25: $767-775$

4 Hokama A, Ihama $Y$, Nakamoto $M$ et al. Esophagitis dissecans superficialis associated with bisphosphonates. Endoscopy 2007; 39 (Suppl. 01): E91

5 Hocaoglu N, Atilla R, Onen F et al. Early-onset pancytopenia and skin ulcer following lowdose methotrexate therapy. Hum Exp Toxicol 2008; 27: 585 - 589
6 Kurian A, Haber R. Methotrexate-induced cutaneous ulcers in a nonpsoriatic patient: case report and review of the literature. J Cutan Med Surg 2011; 15: 275-279

7 Gutierrez-Ureña S, Molina JF, García CO et al. Pancytopenia secondary to methotrexate therapy in rheumatoid arthritis. Arthritis Rheum 1996; 39: 272 - 276

8 Pamuk ON, Kisacik B, Pamuk GE et al. Do impaired memory, cognitive dysfunction and distress play a role in methotrexate-related neutropenia in rheumatoid arthritis patients? A comparative study. Rheumatol Int 2013; 33: 2631-2635

\section{Bibliography}

Dol http://dx.doi.org/

10.1055/s-0033-1359129

Endoscopy 2014; 46: E99-E100

(c) Georg Thieme Verlag KC

Stuttgart · New York

ISSN 0013-726X

\section{Corresponding author}

\section{K. Abbass, MD}

Dayton Veterans Affairs Medical Center Internal medicine

Wright State University, Boonshoft School of Medicine

4100 West 3rd Street

Dayton

Ohio 45428

USA

Fax: +1-937-429-9050

drkhuramabbass@gmail.com 